\title{
ULTRASONOGRAPHY OF PULLED ELBOW
}

\author{
WEERACHAI KOSUWON, BANCHONG MAHAISAVARIYA, SUKIT SAENGNIPANTHKUL, \\ WIROON LAUPATTARAKASEM, POLASAK JIRAWIPOOLWON
}

From Srinakarind Hospital, Khon Kaen, Thailand

We used ultrasonography in ten children with pulled elbow to compare measurements of the radiocapitellar distance (RCD) on the affected and the unaffected sides. Similar measurements were made in a group of ten age-matched normal children. The mean $\mathrm{RCD}$ in pronation of the affected and normal sides in the patients with pulled elbows was $7.2 \mathrm{~mm} \pm 0.7$ and $3.8 \mathrm{~mm} \pm 0.5$, respectively $(p<0.0001)$. In the normal children the mean RCD in pronation was $4.5 \mathrm{~mm} \pm 0.5$.

We conclude that ultrasonography is of value for documenting pulled elbow in children.

J Bone Joint Surg [Br] 1993; 75-B:421-2.

Received 30 January 1992; Accepted after revision 21 August 1992

Pulled elbow is a common injury among infants and children. The diagnosis is usually made from the history and clinical findings and the radiograph is always normal.

We report, for the first time, the use of ultrasonography for documenting pulled elbow in children.

\section{PATIENTS AND METHODS}

We examined ten children with pulled elbow and ten normal children aged from 2 to 5 years. There were seven boys and three girls in each group. The pulled elbows were diagnosed from the history, physical examination and the satisfactory results of manipulation.

Ultrasonography. A real-time apparatus with a $3.5 \mathrm{MHz}$ convex transducer was used (Hitachi, EUB 405, Japan). This is more suitable for imaging superficial structures but the images of the bones were improved by the use of a gel pad.

W. Kosuwon, MSc, MD, Associate Professor

B. Mahaisavariya, MD, Associate Professor

S. Saengnipanthkul, MD, Professor of Orthopaedics

W. Laupattarakasem, MD, Professor of Orthopaedics and Chairman P. Jirawipoolwon, MD, Professor of Orthopaedics

Department of Orthopaedics and Rehabilitation Medicine, Srinakarind

Hospital, Faculty of Medicine, Khon Kaen University, Khon Kaen 40002, Thailand.

Correspondence should be sent to Dr W. Kosuwon.

(C) 1993 British Editorial Society of Bone and Joint Surgery $0301-620 X / 93 / 3540 \$ 2.00$
The children were examined lying supine with the elbow flexed (Fig. 1). Both groups were examined in pronation and in supination. The pulled elbows were examined in pronation before they were manipulated (since this is the position in which the affected elbow lies) and in supination after manipulation. The injured elbows were not examined in pronation after manipulation, in case this caused a recurrence of the subluxation.

The transducer and gel pad were placed on the lateral aspect of the elbow and the radial head and capitellum were identified (Fig. 2). The distance between them, the radiocapitellar distance (RCD), was measured on the ultrasonogram. The images were stored on videotape (Panasonic AG 6200) after deleting the measurement markers. The records were later retrieved and remeasured by an independent examiner who did not know the diagnosis.

\section{RESULTS}

In the normal children the mean RCD in pronation was $4.5 \mathrm{~mm} \pm 0.5$ and in supination it was $6.5 \mathrm{~mm} \pm 0.4$. The RCD on the affected and the unaffected sides in the children with pulled elbows is given in Table $I$.

The mean RCD of the pulled elbows in pronation differed significantly from that of the contralateral elbows $(p<0.0001)$ and from that of the normal elbows $(\mathrm{p}<0.0001)$.

The mean RCD of the pulled elbows in supination

Table I. Ultrasonic measurements of the radiocapitellar distances $(\mathrm{mm})$ in ten pulled elbows, in supination and in pronation. On the affected side the measurements in pronation were made before manipulation and those in supination after manipulation

\begin{tabular}{clllll}
\hline & \multicolumn{2}{l}{ Pronation } & & \multicolumn{2}{l}{ Supination } \\
\cline { 2 - 3 } \cline { 5 - 6 } Cases & Normal side & Afiected side & & Normal side & Afiected side \\
\hline 1 & 5.0 & 6.5 & 6.3 & 6.1 \\
2 & 4.2 & 6.0 & 6.0 & 6.0 \\
3 & 3.5 & 7.5 & 5.5 & 6.0 \\
4 & 3.0 & 8.0 & 6.3 & 6.0 \\
5 & 4.0 & 6.6 & 5.8 & 5.5 \\
6 & 3.5 & 7.5 & 5.5 & 5.7 \\
7 & 4.5 & 7.0 & 6.5 & 7.0 \\
8 & 3.2 & 7.5 & 7.2 & 7.0 \\
9 & 4.0 & 8.0 & 6.0 & 5.7 \\
10 & 3.5 & 8.0 & 6.2 & 6.0 \\
Mean & $3.8 *$ & $7.2 *$ & 6.1 & 6.0 \\
SD & 0.5 & 0.7 & 0.5 & 0.5 \\
\hline
\end{tabular}

$* \mathrm{p}<0.0001$ 

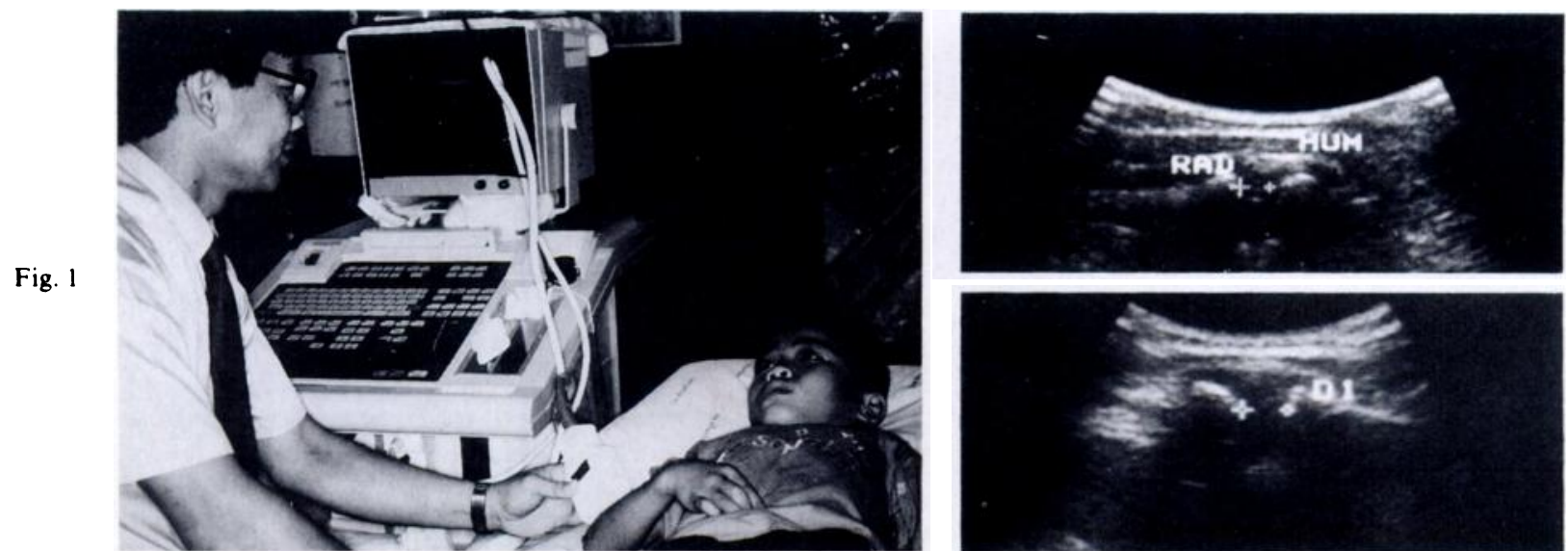

Fig. 2a

Figure 1 - The position of the child and the examiner during ultrasonography of the elbow. Figure 2 - Ultrasonograms in pronation of a normal (a) and a pulled elbow (b). The capitellum and the radial head are highly echogenic $(\mathrm{RAD}=\mathrm{radial}$ head, HUM = capitellum)

(after reduction by manipulation) did not differ significantly from that of the contralateral elbows and of the normal elbows ( $p>0.05$ ).

The correlation coefficients for interobserver variation were 0.85 in the children with pulled elbows and 0.89 in the normal children.

\section{DISCUSSION}

In a pulled elbow the annular ligament slips over the radial head when the forearm is pronated (Stone 1916; McRae and Freeman 1965). The pathological anatomy has been demonstrated in cadavers (Ryan 1969; Salter and Zaltz 1971) but our study is the first to confirm the pathogenesis of pulled elbow in living subjects.

We found that the distance between the radial head and the capitellum was increased in cases of pulled elbow probably due to the interposition of the annular ligament. The reliability of the observations is shown by the high correlation coefficient between the two observers and the statistical significance of the measured differences.

We conclude that ultrasonography can be used to document and confirm the diagnosis of pulled elbow in children.

The authors thank Mr David Narrot for assistance in writing this paper.

No benefits in any form have been received or will be received from a commercial party related directly or indirectly to the subject of this article.

\section{REFERENCES}

McRae R, Freeman PA. The lesion in pulled elbow. J Bone Joint Surg [Br] $1965 ;$ 47-B:808.

Ryan JR. The relationship of the radial head to the radial neck diameters in fetuses and adults with reference to radial head subluxation in children. J Bone Joint Surg [Am] 1969; 51-A :781-3.

Salter RB, Zaltz C. Anatomic investigations of the mechanism of injury and pathologic anatomy of 'pulled elbow' in young children. Clin Orthop 1971; 77:134-43.

Stone CA. Subluxation of the head of the radius: report of a case and anatomical experiments. JAMA 1916;1:28-9. 